\title{
ANALISIS BEBAN KERJA MENTAL PADA STAF UNIT PELAKSANA TEKNIS DENGAN MENGGUNAKAN METODE NASA TLX (STUDI KASUS: UNIVERSITAS TEKNOLOGI SUMBAWA)
}

\author{
1'Jaka Radianza*, ${ }^{2}$ Nurul Hudaningsih, ${ }^{3}$ Silvia Firda Utami
}

Program Studi Teknik Industri, Fakultas Teknik Universitas Teknologi Sumbawa *Corresponding Author email: 1jakajek92@gmail.com, ${ }^{2}$ nurul.hudaningsih@uts.ac.id

\begin{abstract}
Diterima
Bulan September 2019

Diterbitkan bulan Oktober 2019

Keyword: Beban Kerja Mental, UPT UTS, dan NASA TLX.

Abstrak

Aktivitas fisik dan mental merupakan poin utama yang menjadi penyebab terjadinya beban kerja yang umumnya dialami oleh staf. Oleh karena itu, beban kerja dapat dikatakan sebagai suatu hubungan antara kemampuan pekerja dengan besarnya tekanan yang dialami dalam melakukan suatu pekerjaan. Umumnya beban kerja yang sering dialami oleh staf Unit Pelayanan Teknis (UPT) adalah beban kerja mental yang diakibatkan oleh kondisi lingkungan kerja (Universitas), toleransi dalam bekerja dan besarnya tekanan yang dialami dalam pekerjaan tersebut. Lingkup yang menjadi fokus dalam penelitian ini yaitu Universitas Teknologi Sumbawa yang memiliki 10 UPT (UPT Perpustakaan, UPT Pusat Bahasa, UPT Penerimaan Mahasiswa Baru, UPT International Office, UPT Beasiswa, UPT Kerjasama, UPT Teknologi Informasi, UPT Humas dan Protokoler, UPT Ruang Publik Kreatif dan UPT Pengelolaan Hutan Pendidikan dan Penelitian) yang dimana setiap UPT memiliki beban kerja yang berbeda-beda. Pengukuran beban kerja mental dalam penelitian ini menggunakan metode NASA TLX (The National Aeronautics and Space Administration Task Load Index) dengan cara pemberian ratting dan pemberian bobot berupa pengisiaan kuisioner oleh staf di masing-masing UPT. Hasil penelitian menunjukkan bahwa UPT yang memiliki beban kerja mental paling rendah yaitu UPT Perpustakaan $(54,5)$, beban kerja mental sedang yaitu UPT Pusat Bahasa $(77,4)$, beban kerja mental paling tinggi yaitu UPT Beasiswa $(86,4)$.
\end{abstract}

\section{PENDAHULUAN}

Dewasa ini, tuntutan mahasiswa terhadap pelayanan kampus semakin besar, namun profesionalisme yang diharapkan belum sepenunya terwujud. Sikap paling utama yang harus dimiliki staf dalam lingkup Universitas adalah profesional dan sikap ramah. Namun, adakalanya beban kerja yang terlalu besar menyebabkan munculnya sikap yang bertolak belakang seperti kurang ramah dan tidak profesional menyebabkan pelayanan yang diberikan oleh staf kurang memuaskan untuk mahasiswa. Keadaan ini umunya disebabkan oleh aktivitas fisik dan mental yang sering dialami oleh staf di lingkup Universitas.

Aktivitas fisik dan mental merupakan poin utama yang menjadi penyebab terjadinya beban kerja yang umumnya dialami oleh staf. Oleh karena itu, beban kerja dapat dikatakan sebagai suatu hubungan antara kemampuan pekerja dengan besarnya tekanan yang dialami dalam melakukan suatu pekerjaan. Umumnya beban kerja yang sering dialami oleh staf Unit Pelayanan Teknis (UPT) adalah beban kerja mental yang diakibatkan oleh kondisi lingkungan kerja (Universitas), toleransi dalam bekerja dan besarnya tekanan yang dialami dalam pekerjaan tersebut. Lingkup yang menjadi fokus dalam penelitian ini yaitu Universitas Teknologi Sumbawa yang memiliki 10 UPT (UPT
Perpustakaan, UPT Pusat Bahasa, UPT Penerimaan Mahasiswa Baru, UPT International Office, UPT Beasiswa, UPT Kerjasama, UPT Teknologi Informasi, UPT Humas dan Protokoler, UPT Ruang Publik Kreatif dan UPT Pengelolaan Hutan Pendidikan dan Penelitian) yang dimana setiap UPT memiliki beban kerja yang berbeda-beda.

Beban kerja yang dialami oleh staf UPT umumnya disebabkan oleh tekanan dari pekerjaan yang besar namun tidak diimbangi dengan apresiasi yang sesuai. Sehingga menimbulkan tekanan yang akan mempengaruhi pelayanan. Kondisi yang disebabkan oleh beban kerja dapat menyebabkan terjadinya penurunan kualitas pelayanan yang tidak sesuai visi dan misi dari setiap UPT yang ada. Oleh karena itu, dalam penelitian ini akan dilakukan pengukuran beban kerja mental staf UPT dengan kualitas yang sesuai dengan standar pelayanan.

Pengukuran beban kerja mental dapat diklasifikasikan atas dasar metode obyektif dan metode subjektif (Manuaba, 2000). Pengukuran beban kerja mental secara subjektif salah satunya dilakukan dengan menggunakan metode NASA TLX. NASA TLX adalah metode ratting multidimensional yang mampu mengukur secara keseluruhan beban kerja mental berdasarkan bobot rata-rata dari 6 subskala yaitu Mental Demands, Physical Demands, Temporal 
Demands, Own Perfomance, Effort dan Frustation (Hart dan Staveland, 1988).

Adapun penelitian yang serupa yakni pada penelitian Rahadian Ramadhan, Ishardita Pambudi Tama, Remba Yanuar,(2014) dengan judul Analisa Beban Kerja Dengan Menggunakan Work Sampling dan Nasa-Tlx Untuk Menentukan Jumlah Operator (Studi Kasus: PT XYZ) Work Sampling dan Nasa TLX Hasil perhitungan NASA-TLX menunjukkan bahwa beban mental 5 operator adalah 71,4. Setelah penambahan pelaksana mesin di mesin Ring sebanyak 1 orang skor NASA-TLX menjadi 59,49

Pada penelitian ini menggunakan metode NASA TLX karena mempunyai tingkat akurasi paling tinggi karena mempunyai indikator yang rinci (Ragil dkk., 2016). Penelitian ini dilakukan di Universitas Teknologi Sumbawa dengan tujuan mengukur beban kerja mental yang dirasakan oleh staf UPT. Berdasarkan penjelasan tersebut, maka penelitian ini dilakukan dengan judul : "Analisis Beban Kerja Mental pada Staf Unit Pelaksanaan Teknis (UPT) dengan Menggunakan Metode Nasa TLX (Study Kasus: Universitas Teknologi Sumbawa)”.

\section{TINJAUAN PUSTAKA \\ 2.1 Landasan Teori}

\subsubsection{Pengertian Beban Kerja}

Beban kerja (work load) dapat didefinisikan sebagai suatu perbedaan antara kapasitas atau kemampuan pekerjaan dengan tuntutan pekerjaan yang harus dihadapi. Mengingat kerja manusia bersifat mental dan fisik, maka masing-masing mempunyai tingkat pembebanan yang berbeda-beda. Tingkat pembebanan yang terlalu tinggi memungkinkan pemakaian energi yang berlebih dan terjadi "over stress" (Tawaka, 2010).

Beban kerja mental adalah beban kerja yang diterima pekerja untuk menyelesaikan pekerjaannya dengan melibatkan aktivitas mental. Aktifitas mental biasanya di dominasi oleh pekerjaan yang memiliki tanggung jawab yang besar serta pekerjaan yang diharuskan mengambil keputusan (Riyadi, 2014). Gradjean (1993) menyatakan, bahwa setiap aktivitas mental akan selalu melibatkan persepsi, interpretasi, dan proses mental dari suatu informasi yang diterima oleh organ sensoris untuk diambil suatu keputusan atau mengingat informasi yang disimpan.

Beban kerja fisik dapat diartikan sebagai reaksi dari hasil melakukan suatu pekerjaan eksternal yang ditandai dengan perubahan pada konsumsi oksigen, denyut nadi, dan temperatur tubuh. Menurut Riyadi (2014), beban kerja fisik dikelompokkan menjadi tiga yaitu:

1. Kerja total seluruh tubuh, kerja fisik ini menggunakan dua pertiga dari otot tubuh.
2. Kerja sebagian otot, kerja fisik ini membutuhkan energi yang lebih sedikit dikarenakan kinerja otot yang lebih sedikit.

3. Kerja otot statis kerja fisik otot yang menggunakan otot sehingga menghasilkan gaya kontrasi otot.

\subsubsection{Faktor yang Mempengaruhi Beban Kerja Mental}

Menurut Prihatini (2007) faktor yang mempengaruhi beban kerja tersebut antara lain adalah :

\section{1) Beban kerja faktor eksternal}

Beban kerja yang berasal dari luar tubuh pekerja. Beban kerja eksternal yaitu tugas itu sendiri, organisasi, dan lingkungan kerja. Ketiga aspek ini biasanya disebut stressor.

2) Beban kerja karena faktor internal

Faktor yang berasal dari dalam tubuh itu sendiri sebagai akibat adanya reaksi dari beban kerja eksternal. Reaksi tubuh tersebut disebut strain dapat dinilai bak secara objektif maupun subjektif. Penilaian secara objektif, yaitu melalui reaksi fisiologis, sedangkan penilaian subjektif berkaitan dengan harapan, keinginan, kepuasan, dan penilaian subjektif lainnya.

Menurut Hart dan Staveland dalam Prabawati (2012) ada 3 faktor utama yang menentukkan beban kerja mental:

1) Faktor tuntutan tugas (task demand)

Beban kerja dapat ditentukan dari analisis tugas-tugas yang dilakukan oleh pekerja. Bagaimanapun juga, perbedaan-perbedaan secara individu harus selalu diperhitungkan.

2) Usaha atau tenaga (effort)

Jumlah effort yang dikeluarkan pada suatu pekerjaa mungkin merupakan suatu bentuk intuitif secara alamiah terhadap beban kerja. Bagaimanapun juga, sejak terjadinya peningkatan tuntutan tugas, secara individu mungkin tidak dapat meningkatkan effort.

3) Performansi

Sebagian besar studi tentang beban kerja mempunyai perhatian dengan ingkat performansinya yang akan dicapai. Sebagai contoh, secara individu seseorang mungkin akan dapat mengimbangi tuntutan tugas yang meningkat tingkat effort untuk mempertahankan performansi.

Faktor lain yang mempengaruhi seperti kewaspadaan yaitu kemampuan seseorang untuk tetap fokus pada perhatian dan tetap menjaga stimuliti pada target untuk periode waktu yang cukup lama. Kemudian faktor lain juga seperti jenis pekerjaan, situasi pekerjaan waktu respons, waktu penyelesaian yang tersedia dan faktor 
individu seperti, tingkat motivasi, kelelahan, keahlian, kejenuhan, serta toleransi performansi yang diijinkan (Risma, 2010).

Berikut ini merupakan akibat dari beban kerja mental diantaranya :

1) Akibat beban kerja yang terlalu berat dan kemampuan fisik yang lemah, maka akan dapat menyebabkan gangguan penyakit akibat kerja (Lilis, 2007)

2) Kelelahan kerja dan stres psikologis (Rinda I, Zarni A., dan Danardi S., 2011)

Apabila beban kerja lebih besar dari kemampuan tubuh, maka akan terjadi rasa tidak nyaman. Kelelahan, kecelakaan, cedera, rasa sakit, penyakit, dan produktivitas menurun. Sebaliknya, jika beban kerja lebih kecil dari kemampuan tubuh, maka akan terjadi understress, kejenuhan, kebosanan, kelesuan, kurang produktif, dan sakit (Lilis, 2007).

\subsubsection{Metode NASA TLX}

Pengukuran beban kerja harus mempertimbangkan beberapa hal seperti: sensitifitas, kemampuan mendiagnosa, kemampuan menyeleksi, rendah gangguan, kehandalan, dan kemudaan penggunaan. Berdasarkan pertimbangan tersebut NASA TLX (The National Aeronautics and Space Administration Task Load Index) merupakan metode yang telah memenuhi beberapa pertimbangan tersebut (Rubio, Diaz, Martin, \& Puente, 2004). Metode NASA TLX dikembangkan oleh Sandra G. Hart dari NASAAmes Research Center dan Lowell E. Staveland dari san Jose State University (1981). Pengukuran beban kerja NASA TLX adalah sebuah alat yang mengukur beban kerja operator secara subjektif. NASA TLX adalah sebuah prosedur penilaian multi-dimensional yang memperoleh skor beban kerja secara keseluruhannya berdasarkan kepada berat ratarata penilaian 6 sub skala yaitu MD (Mental Demand), OP (Own Perfomance), PD (Physical Demand), FR (Frustation), TD (Temporal Demand), EF (Effort). Penjelasan dari setiap aspek pekerja adalah sebagai berikut:

1. Kebutuhan Fisik: Seberapa banyak pekerjaan ini membutuhkan aktivitas fisik (misalnya: mendorong, mengangkat, memutar, dan lainlain).

2. Kebutuhan Mental: Seberapa besar pekerjaan ini membutuhkan aktivitas mental dan perseptualnya (misalnya: menghitung, mengingat, membandingkan, dan lain-lain).

3. Kebutuhan Waktu: Seberapa besar tekanan waktu pada pekerjaan ini. Apakah pekerjaan ini perlu di selesaikan dengan cepat dan tergesa-gesa, atau sebaliknya dapat dikerjakan dengan santai dan cukup waktu.

4. Performansi: Tingkat keberhasilan dalam pekerjaan. Seberapa puas atas tingkat kinerja yang telah dicapai.
5. Usaha: Seberapa besar tingkat usaha (mental maupun fisik) yang dibuthkan untuk memperoleh performansi yang diinginkan.

6. Tingkat Frustasi: Seberapa besar tingkat frustasi terkait dengan pekerjaan. Apakah pekerjaan menyebalkan, penuh stres, dan tidak memotivasi, ataukah sebaliknya, menyenangkan, santai, dan memuaskan.

Total nilai dari keseluruhan aspek pekerjaan yang dinilai dapat digunakan sebagai evaluasi kuantitatif beban mental atas pekerjaan/aktivitas yang bersangkutan. Metode ini dapat pula diguanakan untuk mengkaji apakah untuk pekerjaan yang sama, beban mental dirasakan oleh para staf UPT.

Aplikasi NASA TLX telah digunakan dalam ekperimen baik yang menggunakan simulator (dalam penerbangan), simulasi pengendalian supervisi atau untuk tugas-tugas dalam ekperimental (memory task, chiceoperation time, critical instability tracking, conpesatortytracking, mental arithmetic, mental rotation, target ocquisition, dan grammatical reasoning). Adapun tahapan dalam metode NASA TLX terdiri dari dua tahap, yaitu tahap pemberian bobot (weights) dan tahap pemberian peringkat (ratings), menurut Mahfira (2018) yaitu:

1) Tahap pemberian bobot (weights)

2) Tahap pemberian ratting

3) Tahap penghitungan Skor

Skor $=$ Bobot $\times$ Rating Nlat

Dimana:

Skor $=$ Nilai KM, KF, KW, PK, TF, U

Nilai Skor didapat dari hasil pengalian antara rating yang dilakukan pada tahap awal dengan bobot faktor pada tahap kedua.

4) Tahap penghitungan Weighted Workload (WWL)

WWL

$=\sum S k O$

Setelah mengukur skor, dilanjutkan dengan mengukur beban kerja terukur. Nilai yang didapat adalah hasil dari penjumlahan skor.

5) Tahap penghitungan skor

Rata - rata WWL

$=\frac{W W L}{n}$

Dimana :

$\mathrm{n}=$ Jumlah perbandingan pada pembobotan $(\mathrm{n}=15)$

Setelah mengukur beban kerja terukur, maka langkah selanjutya adalah mengukur rata-rata 
beban kerja yang mana jumlah produk tersebut dibagi 15 .

6) Tahap interpretasi skor

Berdasarkan penjelasan Hart dan Staveland (1988) dalam teori NASA-TLX, skor beban kerja yang diperoleh dapat di interpretasikan yaitu sebagai berikut:

Tabel 2.1 Interpretasi Skor

\begin{tabular}{|c|c|}
\hline $\begin{array}{c}\text { Golongan Beban } \\
\text { Kerja }\end{array}$ & Nilai \\
\hline Rendah & $0-9$ \\
\hline Sedang & $10-29$ \\
\hline Agak Tinggi & $30-49$ \\
\hline Tinggi & $50-79$ \\
\hline Sangat Tinggi & $80-100$ \\
\hline
\end{tabular}

Sumber : Hard and Staveland (1988)

Penggunaan metode NASA TLX ini umumnya digunakan dalam skala industri yang bertujuan untuk melihat pengaruh dari tekanan yang diberikan dengan beban kerja mental yang dirasakan oleh pekerja produksi. Seperti penelitian yang dilakukan oleh Susetyo (2012) tentang pengaruh beban kerja mental dengan menggunakan metode NASA TLX terhadap stress kerja. Penelitian ini melakukan pengamatan beban kerja mental dan mengklasifikasikan beban kerja mental tersebut menjadi empat kategori yaitu: rendah, sedang, tinggi, dan sangat tinggi pada pekerja pembatik dengan menggunakan metode NASA TLX.

\subsubsection{Dampak Beban Kerja Mental}

Dampak yang ditimbulkan dari beban kerja mental meliputi gejala fisik, gelaja mental dan gejala sosial. Kondisi stres merupakan bentuk dari gejala mental yang umumnya dialami oleh pekerja produksi yang akan berimbas kepada kehidupan sosial dan kondisi fisik.

Menurut Manuaba (2000) stres adalah segala rangsangan atau aksi dari tubuh manusia yang berasal dari luar tubuh maupun dan dalam tubuh itu sendiri yang dapat menimbulkan bermacam-macam dampak merugikan mulai daru menurunkan kesehatan sampai kepada dideritanya suatu penyakit. Beban kerja yang berlebihan atau rendah dapat menimbulkan stress kerja (Lilis, 2007). Menurut Cooper dalam Yudha (2009) sumber stres kerja terdiri dari:

a. Lingkungan kerja ; kondisi kerja yang buruk berpotensi menyebabkan pekerja mudah sakit, mengalami stres dan menurunkan produktivitas.

b. Beban kerja berlebih (work overload); dapat menjadi beban kerja berlebih kuantitatif dan kualitaif. Beban kerja kuantitatif terjadi bila target kerja melebihi kemampuan pekerja yang mengakibatkan mudah lelah. Sedangkan beban kerja berlebih kualitatif terjadi jika pekerjaan memiliki tingkat kesulitan yang tinggi.

c. Deprivational stress ; yaitu pekerjaan yang tidak menarik lagi bagi pekerja, akibatnya timbul berbagai keluhan seperti kebosanan, ketidakpuasan bekerja dan lain sebagainya.

d. Pekerjaan beresiko tinggi yaitu pekerjaan yang berbahaya bagi keselamatan.

\subsubsection{Gambaran Umum Tempat Penelitian}

Penelitian ini dilakukan di Universitas Teknologi Sumbawa ( UTS ) berlokasi di Jalan raya Olat Maras, Batu Alang, Moyo Hulu, Kabupaten Sumbawa NTB. UTS memiliki 10 Unit Pelaksana Teknis ( UPT ).

\section{METODE PENELITIAN}

3.1 Lokasi dan Waktu Penelitian

Penelitian ini dilakukan selama satu semester. Adapun lokasi tempat dilaksanakannya penelitian ini adalah di Universitas Teknologi Sumbawa Jalan Raya Olat Maras, Batu Alang, Moyo Hulu, Sumbawa, NTB.

\subsection{Teknik Pengumpulan Data}

Pengumpulan data menggunakan kuisioner dan dokumentasi. Menurut Churchill (2005), kuisioner merupakan daftar pertanyaan yang digunakan oleh peneliti untuk memperoleh data deri sumber secara langsung melalui pemberian lembar pertanyaan. Kuesioner dalam penelitian ini terdiri dari 6 pertanyaan dengan 15 pembobotan berpasangan. Pada saat pengumpulan data dilakukan, peneliti membimbing satu persatu responden untuk mengisi kuisioner sembari memberikan pertanyaan. Sedangkan dokumentasi dilakukan dengan mengumpulkan data job description dari masing-masing UPT dan Data jumlah staf.

Populasi dari penelitian ini adalah staf di Universitas Teknologi Sumbawa. Teknik penentuan sampel menggunakan purposive sampling yang mana sampel dipilih tidak berdasarkan random, daerah atau strata, melainkan berdasarkan atas adanya pertimbangan yang berfokus pada tujuan tertentu Arikunto (2006). sampel penelitian ini adalah staf di 10 UPT yang memiliki job description masingmasing.

\subsubsection{Jenis Data}

Jenis data yang diperlukan pada tugas akhir ini dibagi menjadi dua yaitu data primer dan data skunder.

\section{a. Data Primer}

Data primer merupakan data asli atau data pertama yang diperoleh dari sumber. Data ini harus dicari melalui narasumber atau dalam istilah teknisnya responden. Data primer dapat diperoleh dengan cara aktif dan pasif. 
Jika secara aktif maka memerlukan responden dalam mendapatkan data. Lalu jika secara pasif maka melakukan observasi terhadap karakteristik-karakteristik tertentu (Noor Hayati, 2011). Pada penelitian ini data diperoleh secara pasif dan aktif. Data yang diperoleh secara aktif yaitu dari hasil kuisioner yang diisi oleh operator serta wawancara yang dilakukan. Kemudian data yang diperoleh secara pasif melalui peninjauan situasi dan kondisi selama produksi berlangsung.

\section{b. Data Sekunder}

Data sekunder adalah yaitu berupa data yang sudah tersedia dan kita hanya perlu mencari dan mengumpulkannya saja. Noor Hayati (2019) berpendapat bahwa data sekunder mudah diperoleh karena ia sudah tersedia misalnya di perpustakaan, biro pusat statistik dan lain-lain . Pada penelitian ini data yang diambil merupakan data dari beberapa sumber mengenai beban kerja mental dengan metode NASA TLX serta penjelasan tentang job desc dari masing-masing UPT.

\subsubsection{Instrumen Penelitian}

Margono dalam Zuriah (2009) mengungkapkan bahwa instrumen penelitian merupakan alat bantu bagi peneliti. Umumnya penelitian akan berhasil dengan baik apabila banyak menggunakan instrument. Ada instrumen yang dipakai untuk mengumpulkan data dalam penelitian ini adalah peneliti sendiri sebagai key instrumen atau peneliti sebagai alat utama. Instrumen kuesioner pada penelitian ini diadopsi dari penelitian terdahulu yang dilakukan oleh Simanjuntak (2010).

Tabel 3.1 Insturmen Kuisioner

\begin{tabular}{|c|c|c|}
\hline Bagian & Isi & keterangan \\
\hline Bagian 1 & $\begin{array}{c}\text { Identitas } \\
\text { Responden }\end{array}$ & $\begin{array}{c}\text { Responden } \\
\text { yang di tunjuk } \\
\text { merupakan } \\
\text { staf dari UPT } \\
\text { di Universitas }\end{array}$ \\
\hline Bagian 2 & Pembobotan & $\begin{array}{c}\text { Berisi tentang } \\
\text { pembandingan } \\
\text { antar indikator }\end{array}$ \\
\hline Bagian 3 & Ratting & $\begin{array}{c}\text { Pemberian } \\
\text { sor di setiap } \\
\text { indikator }\end{array}$ \\
\hline
\end{tabular}

Sumber: Peneliti, 2019

\subsection{Pengolahan Data Menggunakan NASA TLX}

Data yang diambil melalui pengisian kuisioner pada staf UPT selama 1 semester yang dilakukan kepada 30 staf. Pengolahan data yang dilakukan dengan perhitungan beban kerja mental dengan metode NASA TLX.

NASA TLX merupakan suatu metode untuk mengukur beban kerja mental secara subjektif. Dari beberapa metode pengukuran subjektif yang ada, NASA TLX merupakan metode yang terbukti memberikan hasil yang maksimal daripada metode lainnya. Adapun tahapan pengukuran NASA TLX menurut Hancock (1981), yaitu:

1. Tahap pembobotan. Pada tahap ini dipilih satu indikator untuk masing-masing indikator (15 pasang indikator) yang menurut subjek lebih dominan dalam pekerjaannya.

2. Tahap pemberian peringkat. Pada tahap ini operator akan mengisi peringkat dari 6 subskala yang telah diberikan, di antaranya adalah kebutuhan mental (mental demand), kebutuhan fisik (physical demand), kebutuhan waktu (temporal demand), performansi (own performance), usaha (effort) dan tingkat stres (frustration). Nilai yang diberikan dari peringkat tersebut berkisar antara 0 hingga 100 sesuai dengan beban kerja yang dialami operator dalam melakukan pekerjaannya.

3. Setelah melakukan tahap pembobotan, dilanjutkan perhitungan untuk mencari nilai beban kerja psikologis:

a. Mengukur skor ( 2.1 )

b. Mengukur Weighted Workload (WWL) (2.2)

c. Mengukur rata-rata WWL (2.3)

d. Interpretasi hasil nilai skor sesuai pada tabel 2.1

\subsection{Diagram Alur Penelitian}

Penelitian ini dilakukan dengan melalui beberapa tahapan yang dapat dijelaskan dengan menggunakan diagram alur sebagai berikut :

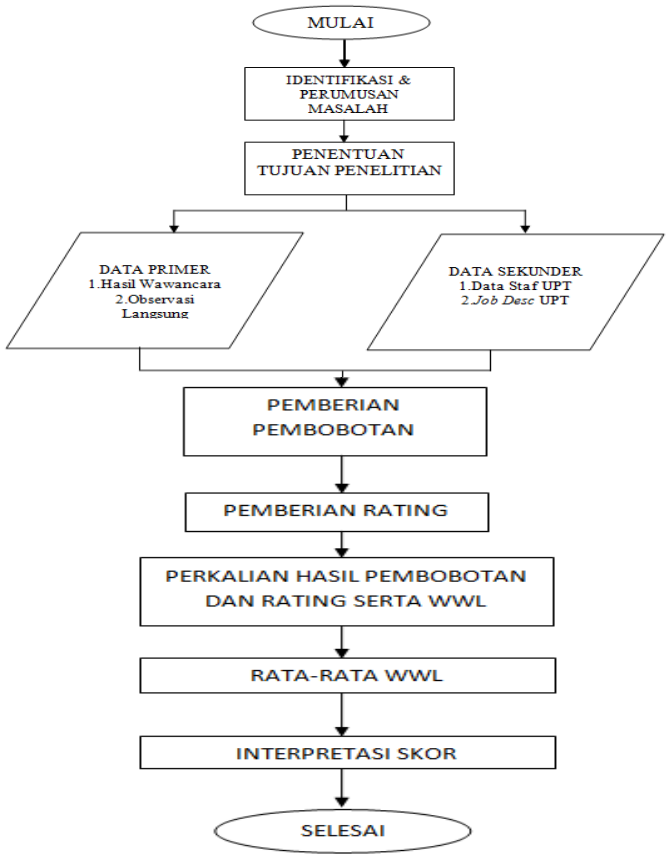

Gambar 3.1 Diagram Alur Penelitian

\section{HASIL DAN PEMBAHASAN}


4.1 Pengolahan Data Beban Kerja Dengan Metode NASA-TLX (National Aeronautics and Space Administration Task Load Index)

Data beban kerja mental dengan menggunakan metode NASA-TLX menggunakan enam indikator yang diukur untuk mengetahui seberapa besar beban kerja yang dialami oleh staf UPT Universitas Teknologi Sumbawa. Indikator tersebut adalah Kebutuhan Mental (KM), Kebutuhan Fisik (KF), Kebutuhan Waktu (KW), Performansi Kerja (PK), Tingkat Frustasi (TF), dan Usaha Fisik dan Mental (U). Pada tahap pemberian bobot yang menyajikan 15 pasangan indikator kemudian diisi oleh staf dengan cara mencentang salah satu pasangan indikator dimana menurut karyawan yang lebih dominan mereka alami.

Pemberian rating merupakan tahap lanjutan setelah dilakukannya tahap pembobotan. Menurut Iridiastadi (2014), tahap pemberian peringkat atau rating pada skala 1-100 diberikan untuk masing-masing indikator sesuai dengan beban kerja yang telah dialami karyawan dalam melakukan pekerjaannya dengan cara memberikan pertanyaan yang sesuai dengan kuisioner (Lampiran 2 dan 3). Adapun jumlah staf dari setiap UPT dapat dilihat pada tabel 4.1. Tabel 4.1 Data jumlah stap pada setiap UPT

\begin{tabular}{|l|l|c|}
\hline No & \multicolumn{1}{|c|}{ UPT } & $\begin{array}{c}\text { Jumlah } \\
\text { Staf }\end{array}$ \\
\hline 1 & UPT Kerjasama & 3 \\
\hline 2 & UPT Pusat Bahasa & 3 \\
\hline 3 & $\begin{array}{l}\text { UPT Penerimaan } \\
\text { Mahasiswa Baru }\end{array}$ & 5 \\
\hline 4 & UPT International Office & 2 \\
\hline 5 & UPT Beasiswa & 5 \\
\hline 6 & UPT Pusat Bahasa & 3 \\
\hline 7 & UPT Humas dan Protokoler & 4 \\
\hline 8 & UPT Perpustakaan & 2 \\
\hline 9 & UPT Teknologi Informasi & 4 \\
\hline 10 & $\begin{array}{l}\text { UPT Pengelolaan Hutan } \\
\text { Pendidikan dan Penelitian }\end{array}$ & 1 \\
\hline & \multicolumn{2}{|c|}{ Total } \\
\hline
\end{tabular}

Sumber : Peneliti

\subsection{Perhitungan WWL (Weight Workload) staf}

Menghitung weighted workload (WWL) bertujuan untuk mendapatkan nilai dari beban kerja tiap indikator. Hasil perhitungan Weighted Workload (WWL) pada staf akan direkapitulasi ke dalam setiap UPT. Berikut rekapitulasi dari hasil perhitungan nilai Weight Workload (WWL) staf pada 10 UPT di Universitas Teknologi Sumbawa.

\subsubsection{UPT Kerjasama}

Untuk mengukur beban mental kerja dari staf UPT Kerjasama dilakukan pengisian kuisioner selanjutnya diolah menggunakan metode NASA TLX dengan hasil rata-rata WWL
UPT Kerjasama seperti yang ditampilkan dalam Tabel 4.2.

Tabel 4.2 Tabel Hasil Perhitungan WWL pada UPT Kerjasama.

\begin{tabular}{|c|c|c|c|c|c|c|c|c|c|c|}
\hline \multirow[b]{2}{*}{ No } & \multirow[b]{2}{*}{ Nama } & \multicolumn{6}{|c|}{ Weight Workload (WWL) } & \multirow{2}{*}{$\begin{array}{l}\text { Total } \\
\text { WWL }\end{array}$} & \multirow{2}{*}{$\begin{array}{c}\text { Rata - } \\
\text { rata } \\
\text { WWL } \\
\end{array}$} & \multirow{2}{*}{$\begin{array}{c}\text { Kategon } \\
\text { Beban } \\
\text { Kerja }\end{array}$} \\
\hline & & KM & $\mathrm{KF}$ & $\mathrm{KW}$ & PK & TF & $\mathrm{U}$ & & & \\
\hline 1 & 2 & 3 & 4 & 5 & 6 & 7 & 8 & 9 & 10 & 11 \\
\hline 1 & $\begin{array}{l}\text { Responden } \\
1\end{array}$ & 180 & 0 & 228 & 328 & 70 & 440 & 1246 & 83 & $\begin{array}{l}\text { Tinggi } \\
\text { Sekali }\end{array}$ \\
\hline 2 & $\begin{array}{l}\text { Responden } \\
2\end{array}$ & 75 & 0 & 450 & 240 & 170 & 340 & 1275 & 85 & $\begin{array}{l}\text { Tinggi } \\
\text { Sekali }\end{array}$ \\
\hline 3 & $\begin{array}{l}\text { Responden } \\
3\end{array}$ & 240 & 160 & 130 & 240 & 150 & 240 & 1160 & 77 & Tinggi \\
\hline & Total & 495 & 160 & 808 & 808 & 390 & 1020 & 3681 & 81,67 & \\
\hline
\end{tabular}

Berdasarkan hasil perhitungan beban kerja mental yang telah dilakukan, bahwa pada UPT Kerjasama dengan indikator kebutuhan mental (KM) sebesar 495, kebutuhan fisik (KF) sebesar 160, kebutuhan waktu (KW) sebesar 808, performansi kerja (PF) sebesar 808, tingkat frustasi (TF) sebesar 390 dan usaha (U) sebesar 1020. Hasil penelitian pada UPT Kerjasama dapat dilihat salah satu indikator yang paling dominan adalah dalam hal usaha (U) yaitu sebesar 1020 .

\subsubsection{UPT Ruang Publik Kreatif}

Untuk mengukur beban mental kerja dari staf UPT Ruang Publik Kreatif dilakukan pengisian kuisioner selanjutnya diolah menggunakan metode NASA TLX dengan hasil rata-rata WWL UPT Ruang Publik Kreatif seperti yang ditampilkan dalam Tabel 4.3.

Tabel 4.3 Tabel Hasil Perhitungan WWL pada UPT RPK

\begin{tabular}{|c|c|c|c|c|c|c|c|c|c|c|}
\hline \multirow[b]{2}{*}{ No } & \multirow[b]{2}{*}{ Nama } & \multicolumn{6}{|c|}{ Weight Workload (WWL) } & \multirow{2}{*}{$\begin{array}{l}\text { Total } \\
\text { WWL }\end{array}$} & \multirow{2}{*}{$\begin{array}{c}\text { Rata - } \\
\text { rata } \\
\text { WWL }\end{array}$} & \multirow{2}{*}{$\begin{array}{c}\text { Kategon } \\
\text { Beban } \\
\text { Kerja }\end{array}$} \\
\hline & & KM & $\mathrm{KF}$ & $\mathrm{KW}$ & PK & TF & $\mathrm{U}$ & & & \\
\hline 1 & 2 & 3 & 4 & 5 & 6 & 7 & 8 & 9 & 10 & 11 \\
\hline 1 & $\begin{array}{l}\text { Responden } \\
4\end{array}$ & 75 & 360 & 0 & 320 & 340 & 140 & 1235 & 82 & $\begin{array}{l}\text { Tinggi } \\
\text { Sekali }\end{array}$ \\
\hline 2 & $\begin{array}{l}\text { Responden } \\
5\end{array}$ & 100 & 0 & 50 & 250 & 100 & 320 & 820 & 55 & $\begin{array}{l}\text { Agak } \\
\text { Tinggi }\end{array}$ \\
\hline 3 & $\begin{array}{l}\text { Responden } \\
6 \\
\end{array}$ & 160 & 225 & 50 & 340 & 116 & 0 & 891 & 59 & Tinggi \\
\hline & Total & 335 & 585 & 100 & 910 & 556 & 460 & 2946 & 65 & \\
\hline
\end{tabular}

Berdasarkan hasil perhitungan beban kerja mental yang telah dilakukan, bahwa pada UPT Ruang Publik Kreatif dengan indikator kebutuhan mental (KM) sebesar 335, kebutuhan fisik (KF) sebesar 585, kebutuhan waktu (KW) sebesar 100, performansi kerja (PK) sebesar 910, tingkat frustasi (TF) sebesar 556 dan usaha (U) sebesar 460 .

\subsubsection{UPT Penerimaan Mahasiswa Baru}

Untuk mengukur beban mental kerja dari staf UPT Penerimaan Mahasiswa Baru dilakukan pengisian kuisioner selanjutnya diolah menggunakan metode NASA TLX dengan hasil rata-rata WWL UPT Penerimaan Mahasiswa Baru seperti yang ditampilkan dalam Tabel 4.4. 
Tabel 4.4 Tabel Hasil Perhitungan WWL pada UPT PMB

\begin{tabular}{|c|c|c|c|c|c|c|c|c|c|c|}
\hline \multirow{2}{*}{ No } & \multirow{2}{*}{ Nama } & \multicolumn{6}{|c|}{ Weight Workload (WWL) } & \multirow{2}{*}{$\begin{array}{l}\text { Total } \\
\text { wWL }\end{array}$} & \multirow{2}{*}{$\begin{array}{l}\text { Rata - } \\
\text { rata } \\
\text { WWL }\end{array}$} & \multirow{2}{*}{$\begin{array}{c}\text { Katego } \\
\text { n } \\
\text { Bebara } \\
\text { Keja }\end{array}$} \\
\hline & & KM & $\mathrm{KF}$ & $\mathrm{KW}$ & PK & TF & $\mathrm{U}$ & & & \\
\hline 1 & 2 & 3 & 4 & 5 & 6 & 7 & 8 & 9 & 10 & 11 \\
\hline 1 & $\begin{array}{l}\text { Responden } \\
7\end{array}$ & 156 & 234 & 160 & 164 & 164 & 312 & 1190 & 79 & Tinggi | \\
\hline 2 & \begin{tabular}{|l|l|} 
Responden \\
8
\end{tabular} & 255 & 160 & 210 & 80 & 150 & 240 & 1095 & 73 & Tingg: \\
\hline 3 & $\begin{array}{l}\text { Responden } \\
9\end{array}$ & 400 & 0 & 120 & 210 & 80 & 180 & 990 & 66 & Tinggi| \\
\hline 4 & $\begin{array}{l}\text { Responden } \\
10\end{array}$ & 90 & 255 & 255 & 425 & 270 & 0 & 1295 & 86 & $\begin{array}{l}\text { Tinggi } \\
\text { Sekali }\end{array}$ \\
\hline 5 & $\begin{array}{l}\text { Responden } \\
11\end{array}$ & 180 & 75 & 97 & 95 & 80 & 90 & 1366 & 91 & $\begin{array}{l}\text { Tinggi: } \\
\text { Sekali }\end{array}$ \\
\hline & Total & 1081 & 724 & 842 & 974 & 744 & 822 & 2285 & 79 & Tinggi| \\
\hline
\end{tabular}

Berdasarkan hasil perhitungan beban kerja mental yang telah dilakukan, bahwa pada UPT Penerimaan Mahasiswa Baru dengan indikator kebutuhan mental (KM) sebesar 1081, kebutuhan fisik (KF) sebesar 724, kebutuhan waktu (KW) sebesar 842, performansi kerja (PK) sebesar 974, tingkat frustasi (TF) sebesar 744 dan usaha (U) sebesar 822.

\subsubsection{UPT International Office}

Untuk mengukur beban mental kerja dari staf UPT International Office dilakukan pengisian kuisioner selanjutnya diolah menggunakan metode NASA TLX dengan hasil rata-rata WWL UPT International Office seperti yang ditampilkan dalam Tabel 4.5 .

Tabel 4.5 Tabel Hasil Perhitungan WWL pada UPT International Office

\begin{tabular}{|c|c|c|c|c|c|c|c|c|c|c|}
\hline \multirow{2}{*}{ No } & \multirow{2}{*}{ Nama } & \multicolumn{6}{|c|}{ Weight Workload (WWL) } & Total & $\begin{array}{c}\text { Rata - } \\
\text { rata } \\
\text { rata } \\
\text { WWL }\end{array}$ & $\begin{array}{c}\text { Kategon } \\
\text { Beban } \\
\text { Kerja }\end{array}$ \\
\hline 1 & 2 & 3 & 4 & 5 & 6 & 7 & 8 & 9 & 10 & 11 \\
\hline 1 & $\begin{array}{l}\text { Responden } \\
12\end{array}$ & 285 & 0 & 60 & 400 & 100 & 240 & 1085 & 72 & Tinggi \\
\hline $\begin{array}{l}12 \\
2\end{array}$ & $\begin{array}{l}\text { Responden } \\
13\end{array}$ & 170 & 0 & 356 & 240 & 320 & 150 & 1236 & 82 & $\begin{array}{l}\text { Tinggi } \\
\text { Sekali }\end{array}$ \\
\hline
\end{tabular}

Berdasarkan hasil perhitungan beban kerja mental yang telah dilakukan, bahwa pada UPT International Office dengan indikator kebutuhan mental (KM) sebesar 455, kebutuhan fisik (KF) sebesar 0, kebutuhan waktu (KW) sebesar 416, performansi kerja (PK) sebesar 640, tingkat frustasi (TF) sebesar 420 dan usaha (U) sebesar 390 .

\subsubsection{UPT Beasiswa}

Untuk mengukur beban mental kerja dari staf UPT Beasiswa dilakukan pengisian kuisioner selanjutnya diolah menggunakan metode NASA TLX dengan hasil rata-rata WWL UPT Beasiswa seperti yang ditampilkan dalam Tabel 4.6 dan Gambar 4.5.
Tabel 4.6 Tabel Hasil Perhitungan WWL pada UPT Beasiswa.

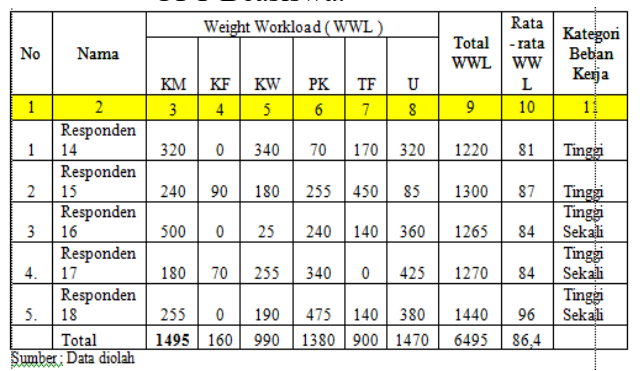

Berdasarkan hasil perhitungan beban kerja mental yang telah dilakukan, bahwa pada UPT Beasiswa dengan indikator kebutuhan mental (KM) sebesar 1495, kebutuhan fisik (KF) sebesar 160, kebutuhan waktu (KW) sebesar 990, performansi kerja (PK) sebesar 1380 tingkat frustasi (TF) sebesar 900 dan usaha (U) sebesar 1470.

\subsubsection{UPT Pusat Bahasa}

Untuk mengukur beban mental kerja dari staf UPT Pusat Bahasa dilakukan pengisian kuisioner selanjutnya diolah menggunakan metode NASA TLX dengan hasil rata-rata WWL UPT Pusat Bahasa seperti yang ditampilkan dalam Tabel 4.7.

Tabel 4.7 Tabel Hasil Perhitungan WWL pada UPT Bahasa.

\begin{tabular}{|c|c|c|c|c|c|c|c|c|c|c|}
\hline \multirow{2}{*}{ No } & \multirow{2}{*}{ Nama } & \multicolumn{6}{|c|}{ Weight Workload (WWL) } & \multirow{2}{*}{$\begin{array}{c}\text { Total } \\
\text { WW } \\
\text { L }\end{array}$} & \multirow{2}{*}{$\begin{array}{c}\text { Rata - } \\
\text { rata } \\
\text { WWL }\end{array}$} & \multirow{2}{*}{$\begin{array}{c}\text { Kategor } \\
\text { Beban } \\
\text { Kerja }\end{array}$} \\
\hline & & $\mathrm{KM}$ & $\mathrm{KF}$ & $\mathrm{KW}$ & PK & TF & $\mathrm{U}$ & & & \\
\hline 1 & 2 & 3 & 4 & 5 & 6 & 7 & 8 & 9 & 10 & 11 \\
\hline 1 & \begin{tabular}{|l|} 
Responden \\
19 \\
\end{tabular} & 237 & 8 & 158 & 320 & 0 & 400 & 1123 & 75 & \\
\hline 2 & $\begin{array}{l}\text { Responden } \\
20\end{array}$ & 270 & 14 & 160 & 400 & 0 & 240 & 1084 & 72 & $\begin{array}{l}\text { Tinggi } \\
\text { Sekali }\end{array}$ \\
\hline 3 & $\begin{array}{l}\text { Responden } \\
21\end{array}$ & 240 & 270 & 140 & 270 & 270 & 85 & 1275 & 85 & $\begin{array}{l}\text { Tinggi } \\
\text { Sekali }\end{array}$ \\
\hline & Total & 747 & 292 & 458 & 990 & 270 & 725 & 3482 & 77,4 & \\
\hline
\end{tabular}

Berdasarkan hasil perhitungan beban kerja mental yang telah dilakukan, bahwa pada UPT Pusat Bahasa dengan indikator kebutuhan mental (KM) sebesar 800, kebutuhan fisik (KF) sebesar 360, kebutuhan waktu (KW) sebesar 660, performansi kerja (PK) sebesar 990, tingkat frustasi (TF) sebesar 890 dan usaha (U) sebesar 490.

\subsubsection{UPT Humas Dan Protokoler}

Untuk mengukur beban mental kerja dari staf UPT Humas dan Protokoler dilakukan pengisian kuisioner selanjutnya diolah menggunakan metode NASA TLX dengan hasil rata-rata WWL UPT Humas dan Protokoler seperti yang ditampilkan dalam Tabel 4.8. 
Tabel 4.8 Tabel Hasil Perhitungan WWL pada UPT Humas dan Protokoler.

\begin{tabular}{|c|c|c|c|c|c|c|c|c|c|c|}
\hline \multirow[b]{2}{*}{ No } & \multirow[b]{2}{*}{ Nama } & \multicolumn{6}{|c|}{ Weight Workload (WWL) } & \multirow{2}{*}{$\begin{array}{l}\text { Total } \\
\text { WWL }\end{array}$} & \multirow{2}{*}{$\begin{array}{l}\text { Rata - } \\
\text { rata } \\
\text { WWL }\end{array}$} & \multirow{2}{*}{$\begin{array}{c}\text { Kategon } \\
\text { Beban } \\
\text { Keria }\end{array}$} \\
\hline & & $\mathrm{KM}$ & $\mathrm{KF}$ & $\mathrm{KW}$ & PK & TF & $\mathrm{U}$ & & & \\
\hline 1 & 2 & 3 & 4 & 5 & 6 & 7 & 8 & 9 & 10 & 11 \\
\hline 1 & $\begin{array}{l}\text { Responden } \\
22\end{array}$ & 77 & 170 & 0 & 360 & 320 & 264 & 1191 & 79 & Tinggi \\
\hline 2 & $\begin{array}{l}\text { Responden } \\
23\end{array}$ & 240 & 70 & 225 & 170 & 280 & 144 & 1129 & 75 & Tinggi \\
\hline 3 & $\begin{array}{l}\text { Responden } \\
24\end{array}$ & 270 & 210 & 25 & 285 & 0 & 400 & 1190 & 79 & Tinggi \\
\hline 4 & $\begin{array}{l}\text { Responden } \\
25\end{array}$ & 180 & 255 & 255 & 160 & 210 & 160 & 1220 & 81 & $\begin{array}{l}\text { Tinggi } \\
\text { Sekali }\end{array}$ \\
\hline & Total & 767 & 705 & 505 & 975 & 810 & 968 & 4730 & 78,5 & \\
\hline
\end{tabular}

Berdasarkan hasil perhitungan beban kerja mental yang telah dilakukan, bahwa pada UPT Humas dan Protokoler dengan indikator kebutuhan mental (KM) sebesar 767, kebutuhan fisik (KF) sebesar 705, kebutuhan waktu (KW) sebesar 505, performansi kerja (PK) sebesar 975, tingkat frustasi (TF) sebesar 810 dan usaha (U) sebesar 968. Hasil penelitian pada UPT Pusat Bahasa dapat dilihat salah satu indikator yang paling dominan adalah dalam hal performansi kerja (PK) sebesar 975.

\subsubsection{UPT Perustakaan}

Untuk mengukur beban mental kerja dari staf UPT Perpustakaan dilakukan pengisian kuisioner selanjutnya diolah menggunakan metode NASA TLX dengan hasil rata-rata WWL UPT Perpustakaan seperti yang ditampilkan dalam Tabel 4.9.

Tabel 4.9 Tabel Hasil Perhitungan WWL pada UPT Perpustakaan.

\begin{tabular}{|c|c|c|c|c|c|c|c|c|c|c|}
\hline \multirow{2}{*}{ No } & \multirow{2}{*}{ Nama } & \multicolumn{6}{|c|}{ Weight Workload (WWL) } & \multirow{2}{*}{$\begin{array}{l}\text { Total } \\
\text { WWL }\end{array}$} & \multirow{2}{*}{$\begin{array}{c}\text { Rata - } \\
\text { rata } \\
\text { WWL }\end{array}$} & \multirow{2}{*}{\begin{tabular}{|l|} 
Kategori \\
Beban \\
Kerja
\end{tabular}} \\
\hline & & KM & $\mathrm{KF}$ & $\mathrm{KW}$ & PK & TF & U & & & \\
\hline 1 & 2 & 3 & 4 & 5 & 6 & 7 & 8 & 9 & 10 & 11 \\
\hline 1 & $\begin{array}{l}\text { Responden } \\
26\end{array}$ & 240 & 158 & 75 & 280 & 0 & 240 & 993 & 66 & Tinggi \\
\hline 2 & $\begin{array}{l}\text { Responden } \\
27\end{array}$ & 80 & 120 & 87 & 116 & 0 & 237 & 640 & 43 & $\begin{array}{l}\text { Agak } \\
\text { Tinggi }\end{array}$ \\
\hline & Total & 320 & 278 & 162 & 396 & 0 & 477 & 1633 & 54,5 & \\
\hline
\end{tabular}

Berdasarkan hasil perhitungan beban kerja mental yang telah dilakukan, bahwa pada UPT Perpustakaan dengan indikator kebutuhan mental (KM) sebesar 320, kebutuhan fisik (KF) sebesar 278, kebutuhan waktu (KW) sebesar 162, performansi kerja (PK) sebesar 396, tingkat frustasi (TF) sebesar 0 dan usaha (U) sebesar 477.

\subsubsection{UPT Teknologi Informasi}

Untuk mengukur beban mental kerja dari staf UPT Perpustakaan dilakukan pengisian kuisioner selanjutnya diolah menggunakan metode NASA TLX dengan hasil rata-rata WWL UPT Perpustakaan seperti yang ditampilkan dalam Tabel 4.10.
Tabel 4.10 Tabel Hasil Perhitungan WWL pada UPT Teknologi Informasi

\begin{tabular}{|c|c|c|c|c|c|c|c|c|c|c|}
\hline \multirow{2}{*}{ No } & \multirow{2}{*}{ Nama } & \multicolumn{6}{|c|}{ Weight Workload (WWL) } & \multirow{2}{*}{$\begin{array}{l}\text { Total } \\
\text { wWL }\end{array}$} & \multirow{2}{*}{$\begin{array}{l}\text { Rata - } \\
\text { rata } \\
\text { WWL }\end{array}$} & \multirow{2}{*}{$\begin{array}{c}\text { Kategon } \\
\text { Beban } \\
\text { Kerja }\end{array}$} \\
\hline & & $\mathrm{KM}$ & $\mathrm{KF}$ & $\mathrm{KW}$ & PK & TF & $\mathrm{U}$ & & & \\
\hline 1 & 2 & & 4 & & & & & 9 & 10 & 11 \\
\hline 1 & $\begin{array}{l}\text { Responden } \\
28\end{array}$ & 170 & 0 & 320 & 160 & 300 & 255 & 1205 & 80 & $\begin{array}{l}\text { Tinggi } \\
\text { Sekali }\end{array}$ \\
\hline 2 & $\begin{array}{l}\text { Responden } \\
29\end{array}$ & 240 & 77 & 160 & 284 & 225 & 140 & 1126 & 75 & Tingg: \\
\hline 3 & $\begin{array}{l}\text { Responden } \\
30\end{array}$ & 160 & 0 & 320 & 170 & 300 & 240 & 1190 & 79 & Tingg: \\
\hline 4 & $\begin{array}{l}\text { Responden } \\
31\end{array}$ & 240 & 75 & 348 & 180 & 280 & 90 & 1213 & 80 & $\begin{array}{l}\text { Tinge: } \\
\text { Sekali }\end{array}$ \\
\hline & & 810 & 152 & 1148 & 794 & 1105 & 725 & 4734 & 78,5 & \\
\hline
\end{tabular}

Berdasarkan hasil perhitungan beban kerja mental yang telah dilakukan, bahwa pada UPT Teknologi Informasi dengan indikator kebutuhan mental (KM) sebesar 810, kebutuhan fisik (KF) sebesar 152, kebutuhan waktu (KW) sebesar 1148, performansi kerja (PK) sebesar 794, tingkat frustasi (TF) sebesar 1105 dan usaha (U) sebesar 725. Hasil penelitian pada UPT Teknologi Informasi dapat dilihat salah satu indikator yang paling dominan adalah dalam hal kebutuhan mental (KM) sebesar 810 .

\subsubsection{UPT Pelaksana Teknis Pengelolaan Hutan, Pendidikan dan Penelitian}

Untuk UPT pengelolaan hutan,peneliti tidak bisa mneguraikan tentang beban kerja serta belum adanya job description yang jelas dari atasan.Selai itu,staf yang ada di UPT sedang tidak berada di tempat,sehingga penliti kesusahan untuk melakukan input data dan penghitungan beban kerja pada staf UPT tersebut.

\subsection{Rekapitulas WWL (Weight Workload) pada setiap UPT}

Berikut hasil rekapitulasi penghitungan weighted workload (WWL) yang dilakukan pada 10 UPT Universitas Teknologi Sumbawa dirangkum dalam tabel di bawah ini: Tabel 4.11 Hasil Perhitungan Rata-rata WWL

\begin{tabular}{|c|l|c|c|}
\hline No & \multicolumn{1}{|c|}{ Nama UPT } & $\begin{array}{c}\text { Rata- } \\
\text { rata } \\
\text { WWL }\end{array}$ & Kategori \\
\hline 1 & $\begin{array}{l}\text { Unit Pelaksana } \\
\text { Teknis Kerja } \\
\text { Sama }\end{array}$ & 81,6 & $\begin{array}{l}\text { Tinggi } \\
\text { Sekali }\end{array}$ \\
\hline 2 & $\begin{array}{l}\text { Unit Pelaksana } \\
\text { Teknik Ruang } \\
\text { Publik Kreatif }\end{array}$ & 65 & Tinggi \\
\hline 3 & $\begin{array}{l}\text { Unit Pelaksana } \\
\text { Teknis } \\
\text { Penerimaan } \\
\text { Mahasiswa Baru }\end{array}$ & 79 & Tinggi \\
\hline 4 & $\begin{array}{l}\text { Unit Pelaksana } \\
\text { Teknis } \\
\text { International } \\
\text { Office }\end{array}$ & 77 & Tinggi \\
\hline 5 & $\begin{array}{l}\text { Unit Pelaksana } \\
\text { Teknis Beasiswa }\end{array}$ & $\mathbf{8 6 , 4}$ & $\begin{array}{l}\text { Tinggi } \\
\text { Sekali }\end{array}$ \\
\hline 6 & $\begin{array}{l}\text { Unit Pelaksana } \\
\text { Teknis Pusat } \\
\text { Bahasa }\end{array}$ & 77,4 & Tinggi \\
\hline
\end{tabular}




\begin{tabular}{l}
\hline Tabel 4.11 Hasil Perhitungan Rata-rata WWL \\
lanjutan \\
\begin{tabular}{|c|l|c|c|}
\hline 7 & $\begin{array}{l}\text { Unit pelaksana } \\
\text { Teknis Humas } \\
\text { dan Protokoler }\end{array}$ & 78,5 & Tinggi \\
\hline 8 & $\begin{array}{l}\text { Unit Pelaksana } \\
\text { Teknis } \\
\text { Perpustakaan }\end{array}$ & 54,5 & Tinggi \\
\hline 9 & $\begin{array}{l}\text { Unit Pelaksana } \\
\text { Teknis Teknologi } \\
\text { Informasi }\end{array}$ & 78,5 & Tinggi \\
\hline \multirow{8}{*}{10} & $\begin{array}{l}\text { Unit Pelaksana } \\
\text { Teknis } \\
\text { Pengelolaan }\end{array}$ & $\begin{array}{l}\text { Hutan, } \\
\text { Pendidikan dan } \\
\text { Penelitian }\end{array}$ & - \\
\hline
\end{tabular}
\end{tabular}

Berdasarkan hasil penelitian dapat diartikan bahwa semua staf UPT mempunyai klasifikasi beban kerja mental yang tinggi, dan yang tertinggi nilainya adalah pada UPT Beasiswa. Faktor yang mempengaruhi tingginya nilai usaha pada UPT beasiswa disebabkan oleh besarnya usaha baik mental dan fisik yang dibutuhkan untuk menyelesaikan pekerjaanya. Menurut hasil penelitian, staf perlu mendapatkan penanganan agar tidak terjadi stress. Rekomendasi yang kami berikan adalah dengan rekreasi atau refreshing secara berkala ke tempat - tempat yang menyenangkan agar fikiran menjadi fresh kembali dan agar dapat meminimalisir terjadinya stress.

\section{PENUTUP}

\subsection{Kesimpulan}

UPT yang memiliki beban kerja mental paling rendah yaitu UPT Perpustakaan $(54,5)$, beban kerja mental sedang yaitu UPT Pusat Bahasa $(77,4)$, beban kerja mental paling tinggi yaitu UPT Beasiswa $(86,4)$.

\subsection{Saran}

Berdasarkan hasil penelitian, maka disarankan sebagai berikut :

1. Hasil penelitian ini kiranya dapat dijadikan referensi oleh mahasiswa mahasiswi selanjutnya, untuk kemudian dapat diperbaharui dengan metode lain atau menggunakan sampel yang berbeda.

2. Kepada Universitas Teknologi Sumbawa, agar memperhatikan beban kerja staf khususnya yang memiliki beban kerja yang tinggi sekali, agar staf mampu melaksanakan tugasnya dengan baik sehingga pelayanan yang diberikan dapat lebih optimum.

\section{DAFTAR PUSTAKA}

Arikunto, S. (2006). Prosedur Penelitian Suatu Pendekatan Praktek. Jakarta: Rineka Cipta.

Churchill, Gilbert A. 2005. "Dasar-Dasar Riset Pemasaran", Edisi 4, Jilid I, Alih
Bahasa Oleh Andriani, Dkk, Penerbit Erlangga, Jakarta.

Grandjean, Etienne. (1993). Fitting The Task to the Man, An Ergonomic Approach, London: Taylor and Francis Publisher.

Hancock \& Meshkati. (1988). Human Mental Workload, Elsevier Science Publisher B.V., New York, USA.

Hart, S. G. (2006), NASA-Task Load Index (NASA-TLX), 20 years later. In Human Factors and Ergonomics Society 50th Annual Meeting (pp. 904-908). Santa Monica, CA: Human Factors and Ergonomics Society.

Hart, S.G. and Staveland, L.E, Development of NASA-TLX (Task Load Index): Results of empirical and theoretical research. Advances in psychology, 52, pp.139 183, 1988.

Lilis Dian Prihatini. (2007). Analisis Hubungan Beban Kerja Dengan Stress Kerja Perawat Di Tiap Ruang Rawat Inap RSUD Sidikalang. Tesis. Medan: Sekolah Pasca Sarjana.

Mahfira, Rizky I., Anres. (2018). Analisis Pengukuran Beban Kerja Mental dan Fisik dengan Kinerja Karyawan Menggunakan Metode NASA-TLX pada Departemen Manufaktur di PT. Petnesia Resindo. Jurnal Teknik Industri. Universitas Tarumanegara:Jakarta.

Manuaba, A. (2000). Kesehatan dan keselamatan Kerja. Surabaya: Guna Widya.

Noor Hayati. (2009). "Statistik Terapan Untuk Penelitian Ilmu-ilmu Sosial Cetakan Keempat". Gajah Mada University Press. Yogyakarta.

Prabawati, R. (2012). Hubungan Beban Kerja Mental Dengan Stress Kerja Pada Perawat Bagian Rawat Inap RSJD Dr. R. M. Soedjarwadi Klaten. Tesis. Surakarta: Program Studi Diploma IV Universitas Sebelas Maret.

Prihatini, L.D., (2007), Analisis Hubungan Beban Kerja Dengan Stres Kerja Perawat Di Tiap Ruang Rawat Inap RSUD Sidikalang, Tesis, Program Studi Ilmu Kesehatan Masyarakat Kekhususan Kesehatan Kerja, Sekolah Pascasarjana, Universitas Sumatera Utara, Medan.

Ragil, M.S., Retno, G., Nashtiti, Aliafari. (2016). Premilinary Study Analisis Beban Kerja Mental di Industri Kreatif. Jurnal Teknik Industri. Universitas Islam Indonesia:Yogyakarta.

Rinda I, Zarni A, dan Danardi S. (2011). Pengaruh Stress Terhadap Kinerja Karyawan. Salemba Humanika, Jakarta.

Risma Adelina Simanjuntak. (2010). Analisis Beban Kerja Mental Dengan Metoda Nasa Task Load Index. Jurusan Teknik Industri, Institut Sains Dan Teknologi AKPRIND Yogyakarta, Vol 3, No 1. 
Riyadi, Irfan Achmad. (2014). Evaluasi Beban Kerja Mental dan Fisik dalam Shift yang Berbeda di Divisi Finishing Printing. Skripsi. Teknik Industri Fakultas Teknik. Universitas Muhammadiyah Surakarta.

Rubio, S., Díaz, E., Martín, J. and Puente, J.M. Evaluation of subjective mental workload: A comparison of SWAT, NASA-TLX, and workload profile methods. Applied Psychology, 53(1), pp.61-86, 2004.

Simanjuntak Risma Adelina, Situmorang Dedi Apriyanto . (2010). "Analisis Pengaruh Shift Kerja Terhadap Beban Kerja Mental Dengan Metode Subjektive Workload Assessment Technique (SWAT)". Jurusan teknik Industri. Fakultas Teknologi Industri InstitutSains \& Teknologi AKPRIND. Yogyakarta.

Susetyo. (2012). Pengaruh Beban Kerja Mental dengan Menggunakan Metode NASATLX Terhadap Stress Kerja. Prosiding SNASI. Yogyakarta.

Tarwaka. (2010). Ergonomi Industri, Dasar-Dasar Pengetahuan Ergonomi dan Aplikasi di Tempat Kerja, Harapan Press:Solo.

Yudha Fandy Prabowo. (2009). Faktor Yang Berhubungan Dengan Kejadian Stres Kerja Pada Bagian Industri Mebel PT.Chia Jian Indosnesia Furniture Di Wedelan Jepara. Skripsi. Semarang.

Zuriah Nuzul, 2009, Metodologi Penelitian Sosial Pendidikan Teori-Aplikasi, Jakarta: PT Bumi Aksara. 
